\title{
Somatosensory evoked magnetic fields from the primary and secondary somatosensory cortices in healthy newborns
}

Citation for published version (APA):

Nevalainen, P., Lauronen, L., Sambeth, A., Wikstrom, H., Okada, Y., \& Pihko, E. (2008). Somatosensory evoked magnetic fields from the primary and secondary somatosensory cortices in healthy newborns. Neuroimage, 40(2), 738-745. https://doi.org/10.1016/j.neuroimage.2007.09.075

Document status and date:

Published: 01/01/2008

DOI:

10.1016/j.neuroimage.2007.09.075

Document Version:

Publisher's PDF, also known as Version of record

\section{Document license:}

Taverne

Please check the document version of this publication:

- A submitted manuscript is the version of the article upon submission and before peer-review. There can be important differences between the submitted version and the official published version of record.

People interested in the research are advised to contact the author for the final version of the publication, or visit the DOI to the publisher's website.

- The final author version and the galley proof are versions of the publication after peer review.

- The final published version features the final layout of the paper including the volume, issue and page numbers.

Link to publication

\footnotetext{
General rights rights.

- You may freely distribute the URL identifying the publication in the public portal. please follow below link for the End User Agreement:

www.umlib.nl/taverne-license

Take down policy

If you believe that this document breaches copyright please contact us at:

repository@maastrichtuniversity.nl

providing details and we will investigate your claim.
}

Copyright and moral rights for the publications made accessible in the public portal are retained by the authors and/or other copyright owners and it is a condition of accessing publications that users recognise and abide by the legal requirements associated with these

- Users may download and print one copy of any publication from the public portal for the purpose of private study or research.

- You may not further distribute the material or use it for any profit-making activity or commercial gain

If the publication is distributed under the terms of Article 25fa of the Dutch Copyright Act, indicated by the "Taverne" license above, 


\title{
Somatosensory evoked magnetic fields from the primary and secondary somatosensory cortices in healthy newborns
}

\author{
Päivi Nevalainen, ${ }^{\mathrm{a}, \mathrm{b}, *}$ Leena Lauronen, ${ }^{\mathrm{a}, \mathrm{b}, \mathrm{c}}$ Anke Sambeth ${ }^{\mathrm{d}}$ Heidi Wikström, ${ }^{\mathrm{a}, \mathrm{b}, \mathrm{e}}$ \\ Yoshio Okada, ${ }^{\mathrm{f}}$ and Elina Pihko ${ }^{\mathrm{a}, \mathrm{b}}$ \\ a BioMag Laboratory, Hospital District of Helsinki and Uusimaa, HUSLAB, Helsinki University Central Hospital, P.O. Box 340, FIN-00029 HUS, Finland \\ ${ }^{\mathrm{b}}$ Helsinki Brain Research Centre, Helsinki, Finland \\ ${ }^{\mathrm{c}}$ Department of Clinical Neurophysiology, Hospital District of Helsinki and Uusimaa, HUSLAB, Helsinki University Central Hospital, Helsinki, Finland \\ ${ }^{\mathrm{d}}$ Department of Neuropsychology and Psychopharmacology, Faculty of Psychology, Maastricht University, The Netherlands \\ e Department of Surgery, Hyvinkää Hospital, Hyvinkää, Finland \\ ${ }^{\mathrm{f}}$ Department of Neurology and UNM BRaIN Center, University of New Mexico School of Medicine, Albuquerque, NM, USA
}

Received 29 May 2007; revised 14 September 2007; accepted 25 September 2007

Available online 27 December 2007

\begin{abstract}
Although brain development has been actively investigated in animals, maturation of the cerebral cortex in human newborns is still poorly understood. This study aimed at characterizing the cortical areas participating in tactile processing in human neonates. Somatosensoryevoked magnetic fields were recorded from 21 healthy full-term newborns during natural sleep. Altogether, four cortical areas were activated by tactile stimulation: the contra- and ipsilateral primary (SI) and secondary (SII) somatosensory cortices. The contralateral SI was activated first in all the newborns. This early activity was not affected by the interstimulus interval or the sleep stage. The contralateral SII activation at around $200 \mathrm{~ms}$ was prominent in quiet sleep (QS) but attenuated in active sleep (AS). Activity in this area was strongly depressed by a faster rate of stimulation. Ipsilateral activity was seen in most subjects: more often in QS than AS. The ipsilateral activity originated from SII in most babies, but in some the ipsilateral SI was also activated. We conclude that both the contra- and ipsilateral SI and SII can participate in the processing of somatosensory information in human neonates.

(C) 2007 Elsevier Inc. All rights reserved.
\end{abstract}

Keywords: Magnetoencephalography (MEG); Neonate; Somatosensoryevoked magnetic field (SEF); Interstimulus interval (ISI); Somatosensory cortex

\footnotetext{
* Corresponding author. BioMag Laboratory, HUCH, P.O. Box 340, FIN00029 HUS, Finland. Fax: +358 947175781.

E-mail address: paivi.nevalainen@helsinki.fi (P. Nevalainen).

Available online on ScienceDirect (www.sciencedirect.com).
}

\section{Introduction}

The somatosensory system may be explored by means of evoked responses recorded either with electroencephalography (EEG) or magnetoencephalography (MEG). EEG detects the electrical potentials on the scalp whereas MEG detects the extracranial magnetic fields, both produced by currents generated in the cerebral cortex. Both types of signal are directly related to neuronal electrical currents and provide excellent temporal resolution. Although both techniques are useful for localization of active cortical areas, MEG offers an important advantage over EEG especially in neonates as it is not affected by the fontanels and sutures of the skull (Flemming et al., 2005; Okada et al., 1999a). The insensitivity to the intervening tissues simplifies the interpretation of MEG signals and improves localization of active cortical areas (Hämäläinen et al., 1993; Okada et al., 1999b).

Both MEG and EEG have been used to identify active cortical areas in humans. In MEG studies of adults, somatosensory stimulation has been shown to activate multiple cortical areas including the contralateral primary somatosensory (SI) cortex at the posterior bank of the central sulcus and bilateral secondary somatosensory (SII) cortices on the upper lip of the Sylvian fissure (for a review, see, e.g., Hari and Forss, 1999). Although the somatosensory evoked potentials in newborns have been studied for decades with EEG (e.g., Manil et al., 1967; Desmedt and Manil, 1970; Gibson et al., 1992), the cortical networks activated by somatosensory stimulation remain largely unknown. However, from topographical maps recorded with multiple electrodes Karniski and colleagues (1992) suggested both contra- and ipsilateral cortical activation to unilateral median nerve stimulation. Recently, neonatal somatosensory evoked magnetic fields (SEFs) have been investigated in three MEG studies (Pihko et al., 2004, 2005; Lauronen et al., 2006). These studies have demonstrated the activation of the 
contralateral SI after both median nerve and tactile stimulation, but the cortical areas activated subsequent to SI have not been unambiguously identified, although proposals have been made (Pihko et al., 2005). Furthermore, the recording in these studies was limited to the contralateral hemisphere.

In this study, we aimed at identifying the cortical generators underlying the neonatal SEFs elicited by tactile stimulation of the contra- and ipsilateral index fingers. Cortical activity was recorded from the right hemisphere when the babies were in natural sleep. In addition, the effect of the stimulus rate on the responses was studied in order to gain further understanding of the functional properties of the cortical generators of the SEFs, and to specify the most appropriate stimulus rate for further neonatal SEF studies.

\section{Materials and methods}

\section{Subjects}

The subjects were 21 full-term healthy newborns (11 females and 10 males). The babies were recruited from the maternity ward of the Helsinki University Central Hospital. The MEG was recorded 1-6 days after birth, with a postmenstrual age between 37 and 42 weeks. The 1-min Apgar score was 10 in one, 9 in fifteen, 8 in three, 7 in one and 5 in one baby (with 5 min follow-up scores of 8 and 10 in the last two babies, respectively). The body weight varied between $2622 \mathrm{~g}$ and $4350 \mathrm{~g}$, the head circumference between $34 \mathrm{~cm}$ and $37.5 \mathrm{~cm}$ and the body length between $46 \mathrm{~cm}$ and $54 \mathrm{~cm}$. All the babies were healthy and their measures were considered adequate for gestational age. The study protocol was approved by the Ethics Committee of the Hospital District of Helsinki and Uusimaa. In each case a parent signed an informed consent form.

\section{Stimulus}

The tactile stimulus was given by a thin plastic membrane surrounded by a harder outer shell. An air puff delivered through a plastic tube (Somatosensory Stimulus Generator, 4-D NeuroImaging Inc., San Diego, USA) expanded the membrane, which then gently tapped on the skin of the newborn's index finger (for more details of the stimulation method, see Pihko et al., 2004). In 11 babies, the contralateral index finger was stimulated with three different ISIs, $0.5,2$ and $4 \mathrm{~s}$, in separate runs. The order of the runs was individually selected depending on the duration of the sleep stages. In the remaining 10 babies, the ISI was constantly $2 \mathrm{~s}$, and the contra- and ipsilateral index fingers were stimulated one at a time in separate runs in individually selected order. For details of the number of subjects recorded in each condition see Table 1.

\section{Data acquisition}

EEG was recorded for sleep stage monitoring with silver-silver chloride disposable electrodes placed at F4, P4 and Cz or P3. The reference electrode was on the left mastoid and the ground on the forehead. Electro-oculography (EOG) was recorded from two electrodes, one above the left and the other below the right eye canthi. MEG was simultaneously recorded with a whole-head helmet-shaped sensor array consisting of 306 independent sensors: 204 gradiometers and 102 magnetometers (Vectorview, Elekta Neuromag Oy, Helsinki, Finland). Both EEG and MEG were band-pass filtered at $0.03-257 \mathrm{~Hz}$. The sampling rate was $987 \mathrm{~Hz}$. The recording took place in a magnetically shielded room (ETS; Lindgren Euroshield Oy, Eura, Finland).
Table 1

Different conditions recorded in each baby

\begin{tabular}{|c|c|c|c|c|c|c|c|c|}
\hline ISI & $2 \mathrm{~s}$ & $2 \mathrm{~s}$ & $2 \mathrm{~s}$ & $2 \mathrm{~s}$ & $0.5 \mathrm{~s}$ & $0.5 \mathrm{~s}$ & $4 \mathrm{~s}$ & $4 \mathrm{~s}$ \\
\hline Sleep stage & QS & AS & QS & $\mathrm{AS}$ & QS & AS & QS & AS \\
\hline Hemisphere & Contra & Contra & Ipsi & Ipsi & Contra & Contra & Contra & Contra \\
\hline Baby 1 & $X$ & $\mathrm{X}$ & $\mathrm{X}$ & $\mathrm{X}$ & & & & \\
\hline Baby 2 & $\mathrm{X}$ & $\mathrm{X}$ & $\mathrm{X}$ & & & & & \\
\hline Baby 3 & $\mathrm{X}$ & $\mathrm{X}$ & $\mathrm{X}$ & & & & & \\
\hline Baby 4 & $\mathrm{X}$ & $\mathrm{X}$ & $\mathrm{X}$ & & & & & \\
\hline Baby 5 & $\mathrm{X}$ & & $\mathrm{X}$ & $\mathrm{X}$ & & & & \\
\hline Baby 6 & $\mathrm{X}$ & $\mathrm{X}$ & & $\mathrm{X}$ & & & & \\
\hline Baby 7 & $\mathrm{X}$ & & $\mathrm{X}$ & $\mathrm{X}$ & & & & \\
\hline Baby 8 & $\mathrm{X}$ & $\mathrm{X}$ & $\mathrm{X}$ & $\mathrm{X}$ & & & & \\
\hline Baby $9\left(^{*}\right)$ & (X) & (X) & & $(\mathrm{X})$ & & & & \\
\hline Baby 10 & $\mathrm{X}$ & $X$ & $X$ & $\mathrm{X}$ & & & & \\
\hline Baby 11 & $\mathrm{X}$ & & & & $\mathrm{X}$ & & $\mathrm{X}$ & $\mathrm{X}$ \\
\hline Baby 12 & $\mathrm{X}$ & & & & X & & $\mathrm{X}$ & \\
\hline Baby 13 & $\mathrm{X}$ & $\mathrm{X}$ & & & $\mathrm{X}$ & & $\mathrm{X}$ & $\mathrm{X}$ \\
\hline Baby 14 & $\mathrm{X}$ & & & & & & $\mathrm{X}$ & $X$ \\
\hline Baby 15 & $\mathrm{X}$ & & & & $\mathrm{X}$ & $\mathrm{X}$ & $\mathrm{X}$ & \\
\hline Baby 16 & $\mathrm{X}$ & & & & $\mathrm{X}$ & & $\mathrm{X}$ & $\mathrm{X}$ \\
\hline Baby 17 & $\mathrm{X}$ & & & & $\mathrm{X}$ & & $\mathrm{X}$ & $X$ \\
\hline Baby 18 & & $\mathrm{X}$ & & & $\mathrm{X}$ & & $\mathrm{X}$ & $\mathrm{X}$ \\
\hline Baby 19 & $\mathrm{X}$ & & & & $\mathrm{X}$ & & $\mathrm{X}$ & $\mathrm{X}$ \\
\hline Baby 20 & $X$ & $\mathrm{X}$ & & & & $\mathrm{X}$ & $\mathrm{X}$ & \\
\hline Baby 21 & $\mathrm{X}$ & $\mathrm{X}$ & & & $\mathrm{X}$ & & $\mathrm{X}$ & $\mathrm{X}$ \\
\hline
\end{tabular}

*Excluded due to a problem with the head digitization, which hampered the equivalent current dipole modeling.

(AS=active sleep; $\mathrm{QS}=$ quiet sleep; contra=contralateral stimulation; ipsi=ipsilateral stimulation; ISI =interstimulus interval).

\section{Procedure}

Prior to the measurement, the three EEG and the two EOG electrodes were attached, along with the ground and the reference electrodes. A cloth cap was then applied over the electrodes. An individual Cartesian coordinate system was defined with a threedimensional digitizer. The preauricular points determined the $x$-axis, which pointed to the right. The nasion established the $y$-axis pointing towards it. The $z$-axis pointed upwards. Four position indicator coils were attached on the cloth cap. The coil positions were determined with the digitizer. When necessary the baby was fed. In neonates, only one hemisphere can be studied at a time, due to the large size of the adult helmet. Thus, the device was tilted into supine position and the baby was placed so that the right hemisphere was downwards close to the sensors. In order to study both contra- and ipsilateral activation, the stimulation was applied first to the contralateral (left) hand and then changed to the ipsilateral (right) hand. One or two researchers were in the room with the baby. The researcher held the stimulator on the baby's index finger, observed the baby's behavior and coded his/her alertness (eyes open/closed) and the behavioral sleep stage onto special trigger channels linked to the raw data file. The complete session with each baby lasted approximately $2 \mathrm{~h}$. The stimulation and the recordings started when the baby was asleep and finished when the baby awoke. The babies were not sedated.

\section{Analysis}

The data were averaged off-line according to the sleep stages (according to Precht1, 1974). EEG, EOG and behavioral coding were used to determine the sleep stage. The sleep stage was characterized 
as quiet sleep (QS) when the baby had his/her eyes closed and a regular respiration pattern, EEG showed high voltage low frequency activity or trace alternant and there were no saccadic eye movements in EOG. In active sleep (AS), the baby had his/her eyes closed and had an irregular respiration pattern. Low-voltage highfrequency signals were seen in EEG and saccadic eye movements in EOG. Periods with non-reliable sleep staging and periods with movement artifacts were left out of analysis (for more details of the protocol, see Pihko et al., 2004). The mean for averaged responses in each session was 250. A spatiotemporal signal space separation method (Taulu and Simola, 2006) served to remove artifacts in MEG in 14 babies. Vector projection removed the cardiac artifact in 2 babies.

The onset of the first response was visually determined from 10 to 14 superimposed gradiometer channel pairs overlying the somatosensory areas (e.g., Fig. 1), as the time when its amplitude exceeded the noise level. The equivalent current dipole (ECD) model was calculated to estimate the location, strength and orientation of the current source. A spherical head model was applied for the analysis. The $x$-, $y$ - and $z$-coordinates of the center of the sphere in the head coordinate system were 0,0 and $30 \mathrm{~mm}$. On average, 19 channel triplets (range 16-23) over the area of interest represented the magnetic field pattern. A time period of $100 \mathrm{~ms}$ before the stimulus was used as the baseline for determining the amplitude of various components. The signals were digitally low-pass filtered at $90 \mathrm{~Hz}$ prior to the analysis. The ECD with the strongest dipole moment determined the peak latency of each deflection. The first ECD, modeled at the peak of the early deflection, was removed from the averaged data before determination of the second ECD. Thereafter, a two-dipole model was constructed to study how well the two ECDs accounted for the whole data. The average goodnessof-fit (GOF, expresses the percentage of the data explained by the ECD) for all dipoles was $88 \%$ (SD 7.7\%). The GOF values of the dipoles accepted for further analysis exceeded $65 \%$. The source orientations were compared in the $y-z$ plane. The orientation of the $y$-axis was considered 0 degrees and that of the $z$-axis 90 degrees.

A two-way analysis of variance (ANOVA) was used to study the differences in the dipole strengths between the sleep stages and between the different ISIs in QS. The strength of the ECDs that could not be modeled with a dipole model was considered zero. Post hoc comparisons were performed with Newman-Keuls test. Peak latencies, ECD source locations and orientations were evaluated with paired, two-tailed t-tests. Statistical significance was considered when $P<0.05$.

\section{Results}

\section{Responses after contralateral stimulation}

SEFs were successfully recorded and analyzed from the right hemisphere in 19 babies in QS and 11 babies in AS after stimulation of the left index finger (contralateral hand) with the 2-s ISI (Table 1). The number of babies in each condition was less than 21 because not all babies slept through both sleep stages in all stimulus conditions. One baby was excluded from the analysis due to a problem with the head digitization, hampering the dipole fitting.

In QS, the response generally consisted of two separate deflections (for a representative newborn, see Fig. 1). The first deflection, M60, started to rise from the baseline at mean 32.4 (SD 5.1) $\mathrm{ms}$ and peaked at 59.9 (9.9) ms. It could be modeled with an ECD in all 19 babies. The second prominent deflection, M200, peaking at 224.3
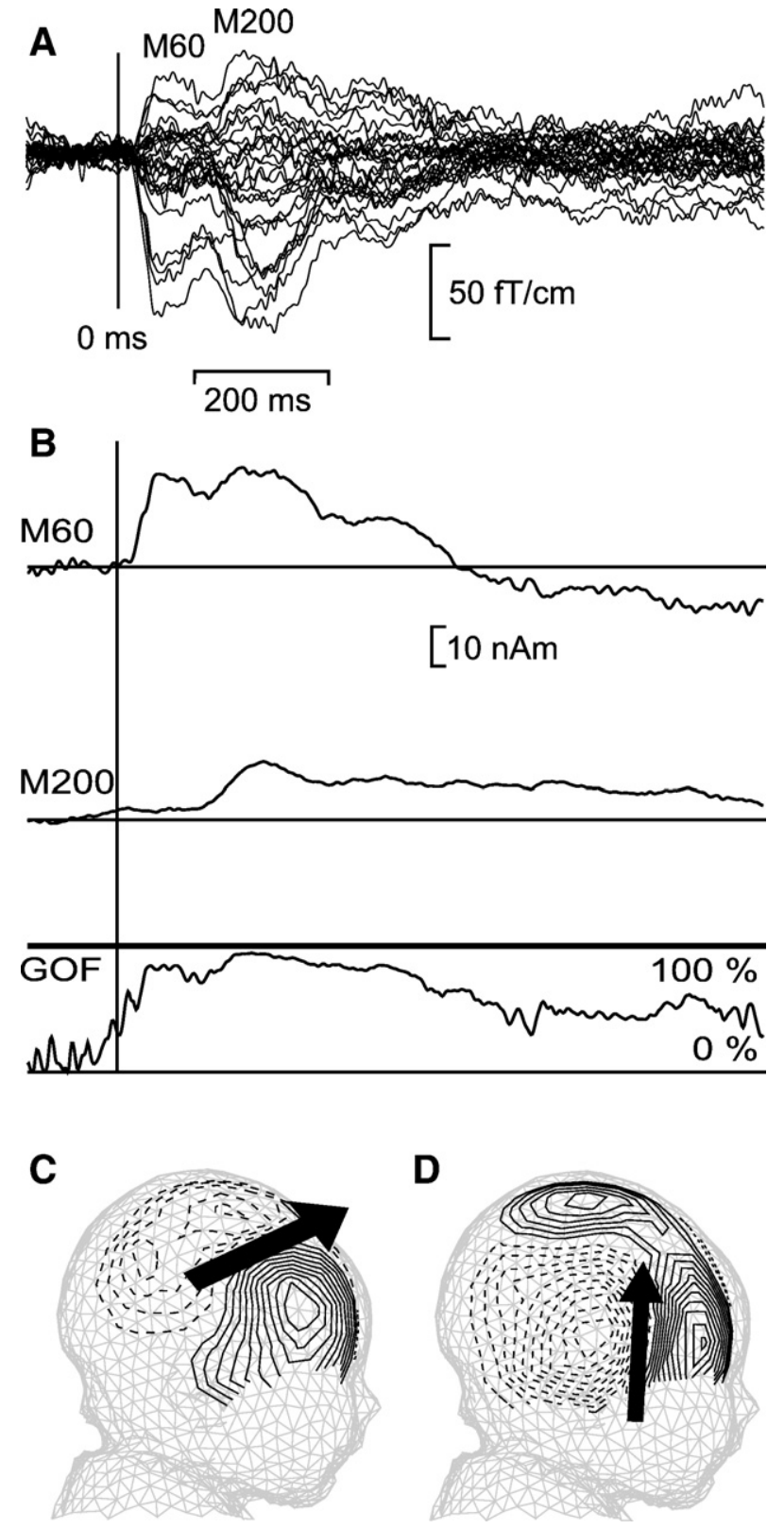

Fig. 1. Multidipole model of the contralateral responses in quiet sleep with an interstimulus interval of $2 \mathrm{~s}$. (A) SEFs from a set of gradiometer channels over the right hemisphere in one baby, showing the M60 and M200 deflections. (B) The top part illustrates the source waveforms of the M60 and M200 ECDs; the goodness-of-fit (GOF) value is shown at the bottom. The two dipole model explains well the data derived from the contralateral hemisphere. (C) The isofield contour map of the M60 is projected on a sphere. The M60 ECD (depicted by an arrow) is horizontally oriented and points anteriorly. (D) The isofield contour map of the M200 ECD after removing the activity of the M60 ECD. The M200 ECD is vertically oriented, pointing superiorly, and its location is inferior to that of the M60 ECD. The contour step is $60 \mathrm{fT} / \mathrm{cm}$, the dashed lines indicate magnetic flux exiting the head and the solid lines magnetic flux entering the head.

(34.1) ms, was visually detected in all 19 babies, but could not be modeled with an ECD in one. The data could be well explained with the two ECDs as shown in Fig. 1. In eight babies, an additional deflection of opposite polarity to M60 was visually detected around 
Table 2

Latencies, source strengths and source orientations of M60 and M200 ECDs with the 2-s ISI

\begin{tabular}{lccccc}
\hline & $\mathrm{nM}$ & $\mathrm{nV} / \mathrm{nD}$ & $\begin{array}{l}\text { Peak latency } \\
(\mathrm{ms})\end{array}$ & $\begin{array}{l}\text { Strength } \\
(\mathrm{nAm})\end{array}$ & $\begin{array}{l}\text { Orientation } \\
\text { (degrees) }\end{array}$ \\
\hline QS M60 & 19 & $19 / 19$ & $59.9(9.9)$ & $11.3(6.3)$ & $10.1(20.3)$ \\
QS M200 & 19 & $19 / 18$ & $224.3(34.1)$ & $11.6(4.8)$ & $80.8(28.1)$ \\
AS M60 & 11 & $10 / 10$ & $61.1(9.6)$ & $9.7(4.5)$ & $12.7(25.3)$ \\
AS M200 & 11 & $10 / 5$ & $216.8(42.1)$ & $7.6(3.4)$ & $92.8(57.6)$
\end{tabular}

Averages with standard deviations in brackets. nM indicates the number of babies recorded in each condition; $\mathrm{nV}$ the number in whom the response was visually detected; and $\mathrm{nD}$ the number of babies whose response could be modeled with a dipole model. ( $\mathrm{QS}=$ quiet sleep; $\mathrm{AS}=$ active sleep; $\mathrm{ECD}=$ equivalent current dipole).

$120 \mathrm{~ms}$; however, the field pattern was not dipolar and the response was left out of further analyses. Because this response could not be reliably modeled with an ECD, it was not removed from the data before determining the M200 response.

In AS, the first deflection started to rise at 31.8 (3.5) ms. It peaked at $61.1(9.6) \mathrm{ms}$ and could be modeled with an ECD in all but one of the 11 babies, whereas M200 could only be modeled in five babies. The latency of M60 did not differ between the sleep stages. The latency of M200 could not be statistically compared between the sleep stages because of the low prevalence of responses in AS. As in QS a deflection around $120 \mathrm{~ms}$ that was visually detected in seven babies was excluded from further analyses. The source strengths differed between the sleep stages [ANOVA $(n=10)$ main effect: $F(1,9)=11.09 ; P<0.01]$. In the post hoc comparisons, the M200 significantly decreased in AS (post hoc: $P<0.05$ ), whereas the change in the strengths of M60 was insignificant. The latencies and the ECD strengths of the M60 and M200 are presented in Table 2.

Both the M60 and the M200 had dipolar field patterns (Fig. 1). The first ECD pointed anteriorly [mean angle in the $y-z$ plane, QS: 10.1 (20.3) degrees; AS: 12.7 (25.3) degrees], whereas the current source underlying the M200 was directed superiorly [QS: 80.8 (28.1) degrees; AS: 92.8 (57.6) degrees] in both sleep stages (Figs. 1 and 2, Table 2). In QS, the average difference [72 (33) degrees] in the orientation in the $y-z$ plane between M60 and M200 was significant. [t-test: $P<0.001(n=18)]$. The number of babies (five) in whom M200 was recorded in AS was inadequate for statistical comparison.

The source origin of the M60 corresponded to the approximate location of the SI area both in AS and QS. The source of the M200 response was more inferior \{mean difference $16 \mathrm{~mm}[P<0.0001$ $(n=18)]$ \} as well as more lateral $\{$ mean difference $7 \mathrm{~mm}[P<0.01$

Fig. 2. Somatosensory evoked responses to contra- and ipsilateral stimulation in quiet (QS) and active (AS) sleep with an interstimulus interval of $2 \mathrm{~s}$. (A) The top part shows the SEFs in QS from a set of gradiometer channels over the right hemisphere in one baby. The M60, pointed out with a line in the waveform graph on the left, has been subtracted from the data before modelling the M200. At the bottom, the isofield contour maps of the M60 and M200 are projected on spheres, showing the field patterns, as well as the ECD (depicted with an arrow) orientations and approximate locations. (B) In AS, corresponding responses, M60 and M200, were present. The ECDs underlying these responses were similar in terms of orientation and location than in QS; however, the M200 response and its ECD are smaller than in QS (the size of the arrow depicting the ECD is proportional to its strength). (C) A late ipsilateral response in QS is seen after stimulation of the right index finger. The location of its ECD coheres with that of the M200 in QS and AS. The contour step is $30 \mathrm{fT} / \mathrm{cm}$, the red lines indicate magnetic flux exiting the head and the blue lines magnetic flux entering the head.
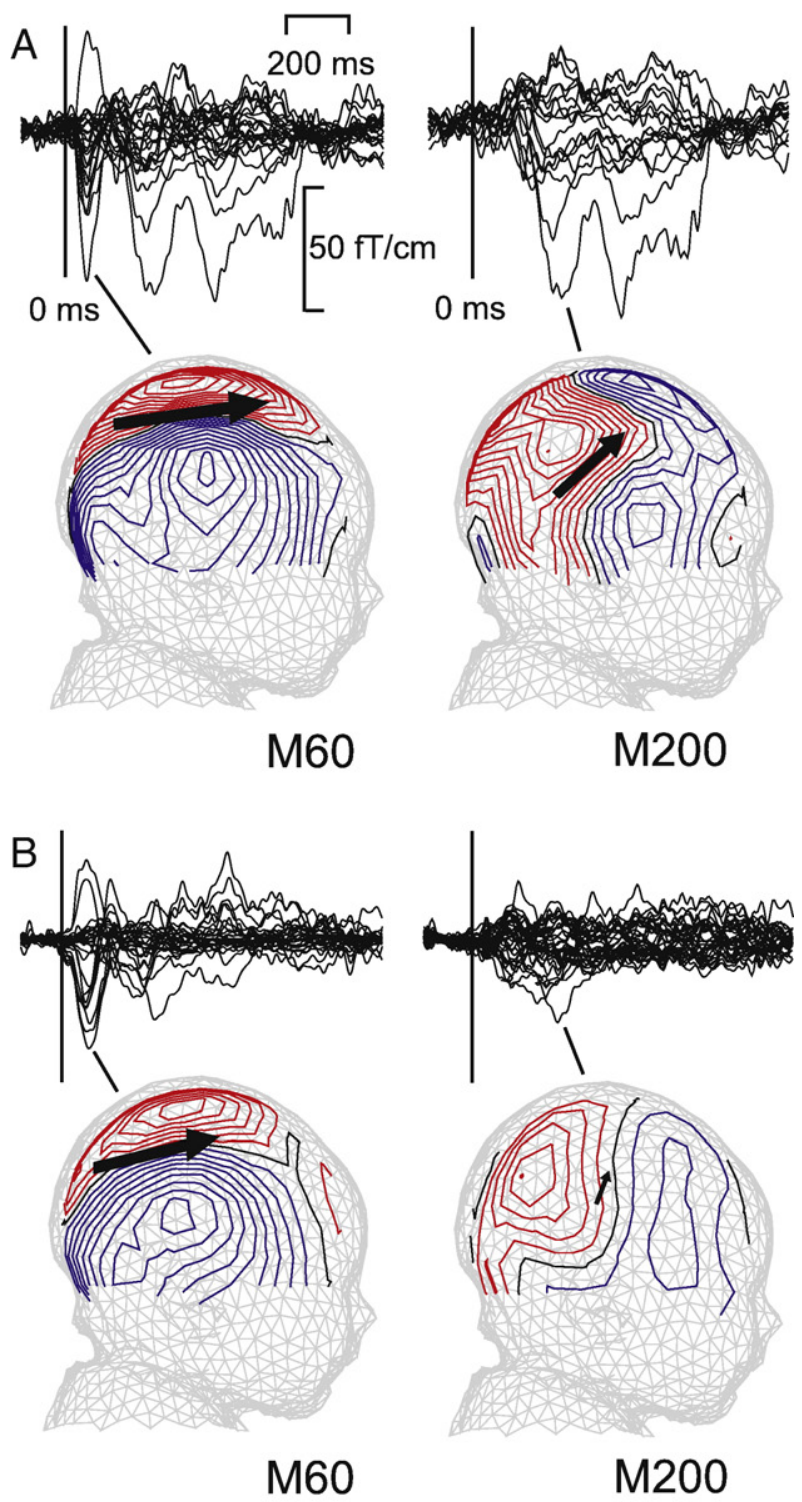

C

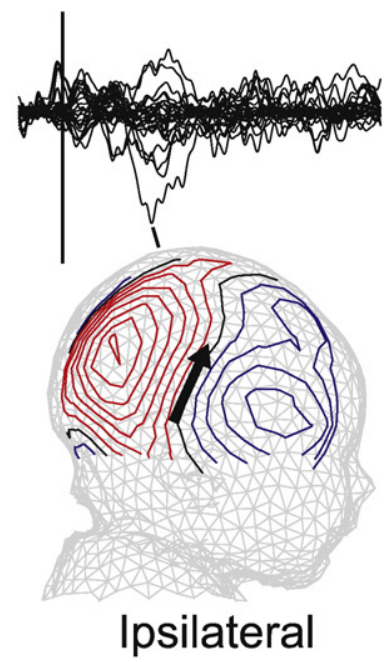


$(n=18)]\}$ (Fig. 3) than the M60 source. The location of the M200 in AS corresponded to that in QS, but could not be statistically compared because of the low number of babies displaying M200 in AS.

\section{Responses after ipsilateral stimulation}

Cortical activity from the right hemisphere was also recorded after stimulation of the right index finger (ipsilateral hand) in ten babies: eight in QS and six in AS (Table 1). In QS, an early response at around $80 \mathrm{~ms}$ was visually detected in two babies and could be modeled in one baby at $77 \mathrm{~ms}$. The source origin was similar to that of the M60 seen after stimulation of the contralateral hand. The underlying current pointed posteriorly. A more prominent later response was visually detected in QS in seven out of eight babies. In five babies, it could be modeled with an ECD peaking at 215.2 (46.1) ms. In one baby, the underlying current orientation and source location corresponded with those of the contralateral M60, while in the other four the superiorly oriented dipole and more inferior location were more similar to the source of the contralateral M200 (Fig. 2). In only one baby were no ipsilateral responses detected in QS. In AS, no responses corresponding to the M60 or M200 were detected. However, similarly to contralateral stimulation, a 120-ms response was seen in five out of six babies, but since the response was not amenable for dipole modeling in four subjects, it was left out from further analyses.

\section{Effect of ISI on the contralateral responses}

In QS, nine out of 11 babies received stimuli on the contralateral hand with ISI of $0.5 \mathrm{~s}$, ten with the 2-s ISI and all 11 with the 4-s ISI. In AS, the number of babies was two, four and eight, respectively (Table 1). Thus, the ISI-effect could be statistically evaluated for QS only.

The source strengths of the responses were affected by the ISI [ANOVA $(n=8)$ main effect: $F(2,14)=11.67 ; P<0.002$ ] (Fig. 4). A

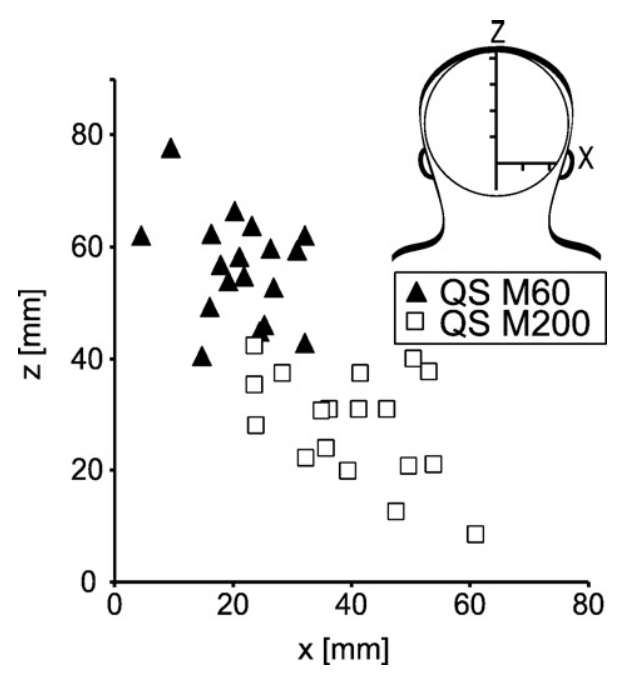

Fig. 3. ECD locations of contralateral M60 and M200 (18 subjects, ISI $2 \mathrm{~s}$ ) in the coronal plane. The black triangles represent the M60 responses and the white squares the M200 responses. The $z$-value indicates the inferiorsuperior and the $x$-value the medio-lateral location. The M200 responses are located significantly more inferiorly and more laterally than the M60 responses. Part of the variance in the locations is due to the varying sizes and shapes of the newborns' heads.

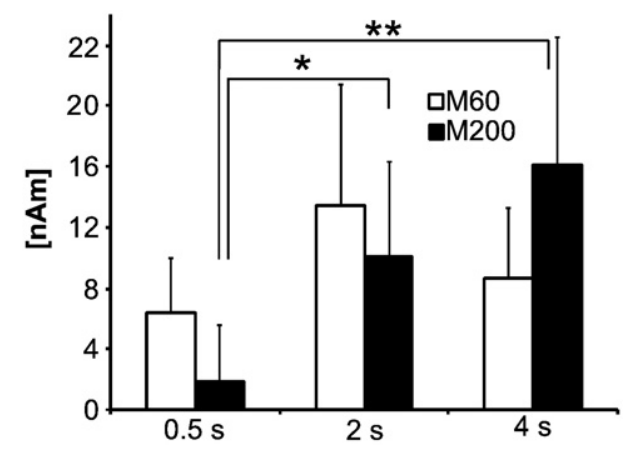

Fig. 4. Source strengths with standard deviations of the M60 (white) and M200 (black) responses with the three ISIs in QS. The M200 is significantly attenuated with the 0.5 -s ISI compared with the longer ISIs. ${ }^{*} P<0.05$, ** $P<0.001$.

two-way interaction for the ISI and the response (M60 and M200) $[F(2,14)=6.94 ; P<0.01]$ indicated that the main effect for ISI could be explained by the significantly smaller strength of the M200 in the 0.5-s condition compared with both the 2-s ISI (post hoc: $P<0.05)$ and 4 -s ISI $(P<0.001)$ conditions. The difference in the strengths of the M200 was not significant between the 2- and the 4-s conditions. The M60 strength was not significantly affected by the ISI. Latencies of M60 and M200 were not affected by the ISI, nor were the locations or current dipole orientations.

\section{Discussion}

This study presents new evidence on the cortical generators underlying the neonatal SEFs. As in our earlier studies, the source location of the M60 corresponded to the contralateral SI cortex (Pihko et al., 2005; Lauronen et al., 2006). The M200 originated from a source inferior and lateral to the M60 source, suggesting its generation at the SII. In adults, the orientations of the ECDs at the SI and the SII are often nearly orthogonal: the SI ECD is oriented horizontally and the SII ECD vertically, consistent with currents perpendicular to the central sulcus and Sylvian fissure, respectively (Hari et al., 1983, 1993; Karhu et al., 1991). Similarly, the neonatal M60 was generated by a horizontal, anteriorly pointing source, while the M200 ECD was vertical and pointed superiorly. These results indicate that both the connections to and the neurons at the SII are sufficiently developed to produce a detectable SEF response at full-term birth. No responses from the contralateral SI with underlying currents pointing posteriorly were seen within the first $100 \mathrm{~ms}$, supporting the results from our earlier study concerning the immaturity of somatosensory processing in neonates (Lauronen et al., 2006). Thus, although both SI and SII can be activated by tactile stimulation, the activation pattern is different from the mature adult responses. The immature SI activation pattern remains at least until 6 months of age (Lauronen et al., 2006).

In addition to the contralateral responses that were present in all subjects, there was ipsilateral activation of SI as well as SII in some babies. In two out of the eight babies in whom ipsilateral hand was stimulated in QS, activity was found at the ipsilateral SI. In subdural SEP recordings, ipsilateral activation of primary somatosensory areas is seen in some adult subjects (Allison et al., 1989; Noachtar et al., 1997). This ipsilateral activity - that is often significantly weaker than the contralateral activity when present (Allison et al., 1989; Noachtar et al., 1997) - is not generally detectable in adults with MEG (e.g., Hari et al., 1984; Hari and Forss, 1999); however, in a 
minority of subjects, ipsilateral SEFs from SI are seen after electrical stimulation of the median nerve at latencies around $50-100 \mathrm{~ms}$ (Korvenoja et al., 1995; Kanno et al., 2003) and after tactile stimulation at $60 \mathrm{~ms}$ (Zhu et al., 2007). In some cases, ipsilateral sensorimotor activation has been shown to result from tactile contamination of the contralateral hand (Hari and Imada, 1999), which does not necessarily exclude true activation of ipsilateral cortex in well-designed measurement settings. With fMRI, positive blood oxygenation level-dependent (BOLD) responses have been detected in area 2 and negative BOLD responses in area $3 b$ to ipsilateral stimulation in adults, contrary to a positive BOLD response seen in both areas after contralateral stimuli (Hlushchuk and Hari, 2006). In sedated newborns, BOLD changes in fMRI have been studied after unilateral passive finger extension-flexion stimuli activating cutaneous and proprioceptive receptors. Responses in SI area did not significantly differ between contra- and ipsilateral hemispheres, supposedly indicating immature cortical lateralization of somatosensory processing (Erberich et al., 2006). Although ipsilateral responses localized at SI were also seen in our study, they were not constantly detected and had longer latencies than the contralateral responses, thus differing significantly from the contralateral responses. This temporal difference between the contra- and ipsilateral SI responses would most likely be unnoticed by fMRI due to poorer temporal resolution. Furthermore, since the stimulation technique in the fMRI study was more robust than the local tactile stimulus of our study, in the fMRI study a more extensive cortical area was most likely activated. Nevertheless, both results indicate that at birth the ipsilateral SI can be activated by somatosensory stimulus.

In addition to the ipsilateral SI activation, a late ipsilateral response in QS could be modeled in four out of eight babies with an ECD. The ECD corresponded better with the contralateral M200 than the M60 in terms of latency, source location and source orientation, suggesting a generator at the ipsilateral SII. Bilateral SII activation after unilateral somatosensory stimulation is also commonly detected in adult MEG studies (e.g., Hari et al., 1983; Hari et al., 1984; Hari and Forss, 1999). As in our study with newborns, the ECD modeling of the ipsilateral SII responses in adults is often more difficult than modeling of the contralateral SII responses, due to a smaller response and lower signal-to-noise ratio (e.g.,Wikström et al., 1997). To our knowledge, activation of the ipsilateral SII has not been previously reported in babies or infants.

The two main responses from the contralateral SI and SII had different ISI dependencies in QS. The source strength of the M200, from the SII, was significantly reduced and even vanished in three babies with the shortest ISI of $0.5 \mathrm{~s}$ compared with the longer ISIs, whereas the M60, from the SI, was not significantly affected. The effect of ISI on SEFs has not been previously investigated in newborns or older infants, and the SEP studies concerning ISI have not considered the cortical generators (Desmedt and Manil, 1970; Araki et al., 1999). However, in adults the SEFs from the SI and SII have different ISI dependencies (Hari et al., 1990, 1993; Forss et al., 1994; Wikström et al., 1996; Hamada et al., 2003). The first SI response after electrical stimulation, N20m, is not significantly diminished by shortening of the ISI from $4 \mathrm{~s}$ to $0.5 \mathrm{~s}$. In contrast, the subsequent SI responses, P35m and P60m, and particularly the SII responses are diminished with the shorter ISIs (Hari et al., 1993; Forss et al., 1994; Forss et al., 1995; Wikström et al., 1996; Hamada et al., 2003). After tactile stimulation, the first prominent cortical response seen at around $50 \mathrm{~ms}$ in adults diminishes with shortening of the ISI in a similar manner as the P35m, which it resembles also in terms of current orientation (Mertens and Lütkenhöner, 2000). In addition, a later response peaking at 70 $100 \mathrm{~ms}$ has been found to be more affected by ISI, but its cortical origin was not determined (Mertens and Lütkenhöner, 2000). The ISI dependencies of the M60 and the M200 in newborns thus share some common features with the adult SEFs from the SI and the SII, respectively. Different experimental conditions (e.g., type of stimulus and state of vigilance) complicate comparison between the present study and these adult studies as discussed below.

In the present study, we used tactile stimulation of the index finger, which has some advantages over the conventional electrical median nerve stimulation. Tactile stimulation resembles a shortlasting natural touch activating the cortical somatosensory area $3 \mathrm{~b}$. In addition, with tactile stimulation artifacts caused by electric stimulation of the small hand, inevitably very close to the MEG sensors, can be avoided. In adults, the first prominent response after tactile stimulation is at around $50 \mathrm{~ms}$, generated by a posteriorly pointing source (Mertens and Lütkenhöner, 2000; Hlushchuk et al., 2004; Lauronen et al., 2006). An earlier response at about $30 \mathrm{~ms}$ with anterior orientation of currents is weaker and not always detected (Lauronen et al., 2006). In newborns, the two types of stimuli differ similarly: the first response at $30 \mathrm{~ms}$ seen after electrical stimulation of the median nerve is not seen after tactile stimulation of the index finger (Lauronen et al., 2006). The M60 is the first clear response after tactile stimulation. A late response, M200 can be seen after both electric and tactile stimulation in neonates (Pihko et al., 2005).

Development of SEP from infancy to adulthood has been investigated by several authors and the neonatal N1 has been shown to mature to the adult N20 (e.g., Desmedt et al., 1976; Willis et al., 1984). However, only few have studied the effect of ISI on SEPs in newborns or older infants (Desmedt and Manil, 1970; Araki et al., 1999), although it has been proposed that a longer ISI is needed for reliable recording of evoked potentials in young infants (Desmedt and Manil, 1970; George and Taylor 1991). For example, the N20 and P23 are most attenuated by short ISI in the group of infants aged 0 to 6 months compared with older infants (Araki et al., 1999). Desmedt and Manil (1970) investigated the late SEP components peaking after $200 \mathrm{~ms}$ in newborns and found their enhancement in QS even at an ISI of $8 \mathrm{~s}$ compared to a 4-s ISI, at least in some individuals. The studies on the development of SEFs are few (Gondo et al., 2001; Lauronen et al., 2006) and the effect of the ISI on SEFs has not been previously investigated in newborns or children. In the present study, we compared the effect of ISI on SEFs at the group level. ISI had no effect on M60, but M200 was attenuated with the 0.5 -s ISI. The differences between the 2- and 4-s ISIs in QS were insignificant even though the ECD of M200 was slightly stronger with the longer ISI. There are some practical advantages in using shorter ISIs since the recording time cannot be easily extended beyond awakening. We suggest $2 \mathrm{~s}$ to be the most suitable ISI for studying the M60 and M200 SEF responses. In addition, an ISI as short as $0.5 \mathrm{~s}$ may be useful for studying M60 in full-term newborns.

The effect of the sleep stage on the M60 was insignificant, which agrees with results from adult studies where the subject's vigilance does not significantly affect the earliest SI responses (Kitamura et al., 1996; Hamada et al., 2003; Kakigi et al., 2003). In our previous study in newborns, the amplitudes of vectorsums (i.e. amplitude of the square root of the sum of squares of two orthogonal gradients measured by the two planar gradiometers of the MEG system used in this study) of M60 (P1) attenuated in AS compared with QS (Pihko et al., 2004). This may indicate a weak 
tendency towards enhanced M60 in QS in neonates not reaching the significance level in our study using ECD strengths. In adults, attention enhances the SII responses (Hamada et al., 2003), while the responses diminish in sleep, at least in stages 1 and 2 of nonREM sleep (Kitamura et al., 1996; Kakigi et al., 2003). The neonatal M200 and the late ipsilateral responses localized to SII were also affected by the sleep stage. They were detected more often in QS than AS, indicating enhancement in non-REM sleep. As in our earlier study, the amplitudes of vectorsums for the M200 (P2) were larger in QS compared with AS (Pihko et al., 2004). Nonetheless, comparison between adults and newborns is difficult because the immature sleep stages of newborns cannot be exactly compared with the sleep stages in adults. Furthermore, the newborns were not recorded in awake state, and SEFs in slow-wave sleep (S3 and S4) and REM sleep have not been recorded in adults.

The enhancement of M200 in QS suggests that sleep stage affects the functional connectivity within the somatosensory system of newborns. In adults, it has been suggested with TMS-evoked responses that in non-REM sleep the effective connectivity breaks down and the brain activity does not spread as widely as in the awake state (Massimini et al., 2005). Although in the neonates the facilitation of the SII response in QS compared to AS might reflect changes in the effective connectivity of the primary and secondary somatosensory areas in the different sleep stages, the mechanisms as well as possible physiological significance remain unknown. Interestingly, it has been argued that the sleep stages, especially AS, serve at least partly different functions in newborns and adults (Marks et al., 1995). Further studies on the development of the somatosensory responses with the appearance of adult-like sleep patterns will be important for clarifying the association between the response morphology and sleep stages.

Based on our results, we suggest that SI and SII are the origins of the most prominent contralateral neonatal SEF responses M60 and M200, respectively. In QS, prominent cortical activation was detected also after ipsilateral stimulation. The most probable generators of the ipsilateral responses are the SII and sometimes SI. The attenuation of the contralateral SII response with frequent stimulation is in accordance with results from adults, but the effect of the sleep stage compared with adults still remains to be confirmed. The somatosensory system of a newborn appears to be mature enough to produce constant, detectable SEF responses at the contralateral SI and SII and sometimes from the ipsilateral SI and SII, but certain features of the responses including the facilitatory effect of QS on the M200 responses from the SII may represent immaturity of somatosensory processing at this early state of development.

\section{Acknowledgments}

We wish to express our gratitude to our subjects and their families for preparing the way for this study. Furthermore, we would like to thank Mr. Lauri Parkkonen for his help in preparing the figures. The study was financially supported by the Jenny and Antti Wihuri Foundation, the Instrumentarium Science Foundation, the Sigrid Jusélius Foundation, the Academy of Finland and Helsinki University Central Hospital Research Grants.

\section{References}

Allison, T., McCarthy, G., Wood, C.C., Williamson, P.D., Spencer, D.D., 1989. Human cortical potentials evoked by stimulation of the median nerve. II. Cytoarchitectonic areas generating long-latency activity. J. Neurophysiol. 62, 711-722.
Araki, A., Takada, A., Yasuhara, A., Kobayashi, Y., 1999. The effects of stimulus rates on the amplitude of the median nerve somatosensory evoked potentials: the developmental change. Brain Develop. 21, 118-121.

Desmedt, J.E., Manil, J., 1970. Somatosensory evoked potentials of the normal human neonate in REM sleep, in slow wave sleep and in waking. Electroencephalogr. Clin. Neurophysiol. 29, 113-126.

Desmedt, J.E., Brunko, E., Debecker, J., 1976. Maturation of the somatosensory evoked potentials in normal infants and children, with special reference to the early N1 component. Electroencephalogr. Clin. Neurophysiol. 40, 43-58.

Erberich, S.G., Panigrahy, A., Friedlich, P., Seri, I., Nelson, M.D., Gilles, F., 2006. Somatosensory lateralization in the newborn brain. Neuroimage $29,155-161$.

Flemming, L., Wang, Y., Caprihan, A., Eiselt, M., Haueisen, J., Okada, Y., 2005. Evaluation of the distortion of EEG signals caused by a hole in the skull mimicking the fontanel in the skull of human neonates. Clin. Neurophysiol. 116, 1141-1152.

Forss, N., Hari, R., Salmelin, R., Ahonen, A., Hämäläinen, M., Kajola, M., Knuutila, J., Simola, J., 1994. Activation of the human posterior parietal cortex by median nerve stimulation. Exp. Brain Res. 99, 309-315.

Forss, N., Jousmäki, V., Hari, R., 1995. Interaction between afferent input from different fingers in human somatosensory cortex. Brain Res. 685, 68-76.

George, S.R., Taylor, M.J., 1991. Somatosensory evoked potentials in neonates and infants: developmental and normative data. Electroencephalogr. Clin. Neurophysiol. 80, 94-102.

Gibson, N.A., Brexinova, V., Levene, M.I., 1992. Somatosensory evoked potentials in the term newborn. Electroencephalogr. Clin. Neurophysiol. $84,26-31$.

Gondo, K., Tobimatsu, S., Kira, R., Tokunaga, Y., Yamamoto, T., Hara, T., 2001. A magnetoencephalographic study on development of the somatosensory cortex in infants. NeuroReport 12, 3227-3231.

Hamada, Y., Okita, H., Suzuki, R., 2003. Effect of interstimulus interval on attentional modulation of cortical activities in human somatosensory areas. Clin. Neurophysiol. 114, 548-555.

Hari, R., Forss, N., 1999. Magnetoencephalography in the study of human somatosensory cortical processing. Philos. Trans. R. Soc. Lond., B 354, 1145-1154.

Hari, R., Imada, T., 1999. Ipsilateral movement-evoked fields reconsidered. Neuroimage 10, 582-588.

Hari, R., Hämäläinen, M., Kaukoranta, E., Reinikainen, K., Teszner, D., 1983. Neuromagnetic responses from the second somatosensory cortex in man. Acta Neurol. Scand. 68, 207-212.

Hari, R., Reinikainen, K., Kaukoranta, E., Hämäläinen, M., Ilmoniemi, R., Penttinen, A., Salminen, J., Teszner, D., 1984. Somatosensory evoked cerebral magnetic fields from SI and SII in man. Electroencephalogr. Clin. Neurophysiol. 57, 254-263.

Hari, R., Hämäläinen, H., Tiihonen, J., Kekoni, J., Sams, M., Hämäläinen, M., 1990. Separate finger representations at the human secondary somatosensory cortex. Neuroscience 37, 245-249.

Hari, R., Karhu, J., Hämäläinen, M., Knuutila, J., Salonen, O., Sams, M., Vilkman, V., 1993. Functional organization of the human first and second somatosensory cortices: a neuromagnetic study. Eur. J. Neurosc. 5, 724-734.

Hlushchuk, Y., Hari, R., 2006. Transient suppression of ipsilateral primary somatosensory cortex during tactile finger stimulation. J. Neurosci. 26, 5819-5824.

Hlushchuk, Y., Forss, N., Hari, R., 2004. Distal-to-proximal representation of volar index finger in human area 3b. Neuroimage 21, 696-700.

Hämäläinen, M., Hari, R., Ilmoniemi, R.J., Knuutila, J., Lounasmaa, O.V., 1993. Magnetoencephalography - theory, instrumentation, and applications to noninvasive studies of the working human brain. Rev. Mod. Phys. 65, 413-497.

Kakigi, R., Naka, D., Okusa, T., Wang, X., Inui, K., Qiu, Y., Tran, T.D., Miki, K., Tamura, Y., Nguyen, T.B., Watanabe, S., Hoshiyama, M., 2003. Sensory perception during sleep in humans: a magnetoencephalographic study. Sleep Med. 4, 493-507. 
Kanno, A., Nakasato, N., Hatanaka, K., Yoshimoto, T., 2003. Ipsilateral area $3 \mathrm{~b}$ responses to median nerve somatosensory stimulation. Neuroimage $18,169-177$.

Karhu, J., Hari, R., Lu, S.-T., Paetau, R., Rif, J., 1991. Cerebral magnetic fields to lingual stimulation. Electroencephalogr. Clin. Neurophysiol. 80, 459-468.

Karniski, W., Wyble, L., Lease, L., Blair, R.C., 1992. The late somatosensory evoked potential in premature and term infants. II. Topography and latency development. Electroencephalogr. Clin. Neurophysiol. 84, 44-54.

Kitamura, Y., Kakigi, R., Hoshiyama, M., Koyama, S., Nakamura, A., 1996. Effects of sleep on somatosensory evoked responses in human: a magnetoencephalographic study. Cogn. Brain Res. 4, 275-279.

Korvenoja, A., Wikstrom, H., Huttunen, J., Virtanen, J., Laine, P., Aronen, H.J., Seppalainen, A.M., 1995. Activation of ipsilateral primary sensorimotor cortex by median nerve stimulation. Neuroreport 6, 2589-2593.

Lauronen, L., Nevalainen, P., Okada, Y., Wikström, H., Parkkonen, L., Pihko, E., 2006. Immaturity of somatosensory cortical processing in human newborns. Neuroimage 33, 195-203.

Manil, J., Desmedt, J.E., Debecker, J., Chorazyna, H., 1967. Les potentiels cérébraux évoqués par la stimulation de la main chez le nouveau-né normal. Rev. Neurol. 117, 53-61.

Marks, G.A., Shaffery, J.P., Oksenberg, A., Speciale, S.G., Roffwarg, H.P., 1995. A functional role for REM sleep in brain maturation. Behav. Brain Res. 69, 1-11.

Massimini, M., Ferrarelli, F., Huber, R., Esser, S.K., Singh, H., Tononi, G., 2005. Breakdown of cortical effective connectivity during sleep. Science 309, 2228-2232.

Mertens, M., Lütkenhöner, B., 2000. Efficient neuromagnetic determination of landmarks in the somatosensory cortex. Clin. Neurophysiol. 111, 1478-1487.

Noachtar, S., Lüders, H.O., Dinner, D.S., Klem, G., 1997. Ipsilateral median somatosensory evoked potentials recorded from human somatosensory cortex. Electroencephalogr. Clin. Neurophysiol. 104, 189-198.
Okada, Y.C., Lähteenmäki, A., Xu, C., 1999a. Experimental analysis of distortion of MEG signals by the skull. Clin. Neurophysiol. 110, 230-238.

Okada, Y., Lähteenmäki, A., Xu, C., 1999b. Comparison of MEG and EEG on the basis of somatic evoked responses elicited by stimulation of the snout in the juvenile swine. Clin. Neurophysiol. 110, 214-229.

Prechtl, H.F.R., 1974. The behavioural states of the newborn infant. Brain Res. 76, 185-212.

Pihko, E., Lauronen, L., Wikström, H., Taulu, S., Nurminen, J., KivitieKallio, S., Okada, Y., 2004. Somatosensory evoked potentials and magnetic fields elicited by tactile stimulation of the hand during active and quiet sleep in newborns. Clin. Neurophysiol. 115, 448-455.

Pihko, E., Lauronen, L., Wikström, H., Parkkonen, L., Okada, Y., 2005. Somatosensory evoked magnetic fields to median nerve stimulation in newborns. Int. Congr. Ser. 1278, 211-214.

Taulu, S., Simola, J., 2006. Spatiotemporal signal space separation method for rejecting nearby interference in MEG measurements. Phys. Med. Biol. 51, 1759-1768

Wikström, H., Huttunen, J., Korvenoja, A., Virtanen, J., Salonen, O., Aronen, H., Ilmoniemi, R.J., 1996. Effects of interstimulus interval on somatosensory evoked magnetic fields (SEFs): a hypothesis concerning SEF generation at the primary sensorimotor cortex. Electroencephalogr. Clin. Neurophysiol. 100, 479-487.

Wikström, H., Roine, R.O., Salonen, O., Aronen, H.J., Virtanen, J., Ilmoniemi, R.J., Huttunen, J., 1997. Somatosensory evoked magnetic fields to median nerve stimulation: interhemispheric differences in a normal population. Electroencephalogr. Clin. Neurophysiol. 104, 480-487.

Willis, J., Seales, D., Frazier, E., 1984. Short latency somatosensory evoked potentials in infants. Electroencephalogr. Clin. Neurophysiol. 59, 366-373.

Zhu, Z., Disbrow, E.A., Zumer, J.M., McGonigle, D.J., Nagarajan, S.S., 2007. Spatiotemporal integration of tactile information in human somatosensory cortex. BMC Neurosci. 8, 21. 